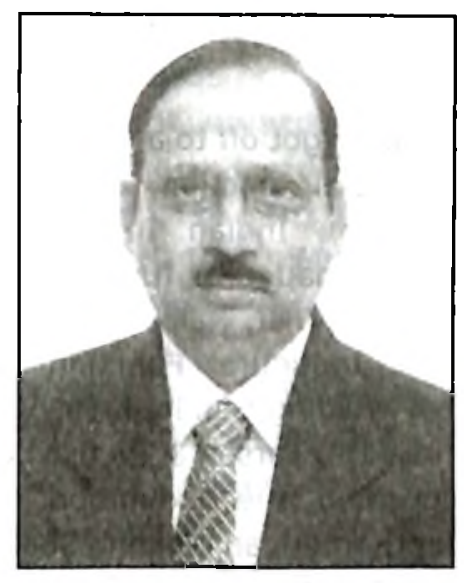

Dear Members,

At the outset I must congratulate Chennai Branch for successfully organizing the National Welding Seminar (NWS-2006) \& the Welding Exhibition (WELD INDIA 2006) held in Chennai from 24-26 November, 2006 .As you are aware, they have further been given the responsibility to conduct the forthcoming mega event i.e. International Welding Congress (IIW-IC-2008) scheduled for 8-10th January 2008 at Chennai and I have no doubt that this event will also be a great success.

You will be happy to know that during NWS-2006 at Chennai on 25th November, 2006 the 3rd convocation of AM-IIW Examination was also held. Prof. S Ranganathan, Vice-Chancellor, Bharat University, Chennai was the Chief Guest for this occasion and final Degree Certificates were handed over to 9 successful candidates on this occasion by him.

Just after the convocation, the third Annual Members Assembly was held and was attended by a large number of members who actively participated in the discussion and expressed their valued opinion and suggestions for the growth of the Institute.

We are happy to inform you that Dr Baldev Raj, a past president of our institute, an eminent scientist and Director- Indira Gandhi Centre for Atomic Research, Kalpakkam, Chennai and also one of the directors of the International Institute of Welding was awarded the country's prestigious PADMASHREE AWARD for this year by the Govt. of India. The Award was announced on the eve of Republic Day this year. We are proud of him and of his contributions over the years in Science \& Technology. I take this opportunity to heartily congratulate Dr Baldev Raj.on behalf of members of our institute.

You are also aware that our Institute has already received the preliminary recognition from IAB towards becoming only Authorized National Body from India. The final audit preparation is on the process.

The Indian Welding Journal is the main official organ of this Institute is published mostly within scheduled time now. To make this journal a vibrant media we need contributions from all of you through submission of articles and advertisements. Hope, you would help us in this.

Let us work together to take this Institute to a greater height.

With warm regards

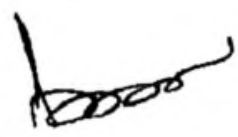

\title{
Parimal Biswas
}

Email : Parimal.Biswas@ril.com 